\title{
Add-on Lamotrigine Treatment for Subsyndromal Depression after Manic or Mixed States in Bipolar Disorder Improved the Quality of Life
}

\author{
Katsumasa Muneoka, ${ }^{1,2}$ Katsushi Kon,, ${ }^{1}$ Masaharu Kawabe, ${ }^{1}$ \\ Rui Ui, ${ }^{1}$ Taichi Miura, ${ }^{1}$ Touta Iimura, ${ }^{1}$ and Shou Kimura ${ }^{1}$ \\ ${ }^{1}$ Kimura Hospital, 6-19 Higashi-Honcho, Chuo-Ku, Chiba, Chiba-shi 260-0004, Japan \\ ${ }^{2}$ Department of Psychiatry, Graduate School of Medicine, Chiba University, Chiba 260-8670, Japan \\ Correspondence should be addressed to Katsumasa Muneoka, kmuneoka@med.showa-u.ac.jp \\ Received 27 May 2012; Accepted 30 August 2012 \\ Academic Editor: B. Carpiniello
}

Copyright @ $\odot 212$ Katsumasa Muneoka et al. This is an open access article distributed under the Creative Commons Attribution License, which permits unrestricted use, distribution, and reproduction in any medium, provided the original work is properly cited.

\begin{abstract}
Two cases of patients experienced subsyndromal depression after manic or mixed hypomanic and depressive episodes due to bipolar I (case 1) and II (case 2) disorders prior to the use of lamotrigine. Case 1 showed episodes of mood switching induced by antidepressants and seasonal mood instability. Case 2 showed hippocampal atrophy and a persistent dull headache that preceded the use of lamotrigine. Both were successfully treated with add-on lamotrigine therapy, and the dull headache was effectively treated with olanzapine. Both patients improved in social activity and work performance after these add-on treatments. Thus, add-on treatment with lamotrigine alone or in combination with olanzapine was an effective strategy to improve the quality of life in bipolar depression. Subsyndromal depression that present after the disappearance of the manic or mixed state was suggested to be practical indication for the use of lamotrigine.
\end{abstract}

\section{Introduction}

Recent reports have demonstrated that, in bipolar I and II disorders, patients spent over threefold more time in depression than in manic or hypomanic symptoms [1-3]. Depression was reported to affect the quality of life (QOL) or subjective life satisfaction in patients with bipolar disorders [4-6]. Therefore, depressive states in bipolar disorders are a primary reason for functional difficulties and social impairment.

It has been proposed that bipolar depression warrants pharmacotherapy distinct from that for unipolar depression. Antidepressants have limited effectiveness [7, 8], and they run the risk of inducing mania $[9,10]$. Although acute mania could be effectively treated with typical mood stabilizers, including lithium, valproate, or carbamazepine, or with firstand second-generation antipsychotics, these medications do not seem to be always suitable for treating bipolar depression
[11]. However, both quetiapine and olanzapine are secondgeneration antipsychotic agents and both have been shown to be accompanied by efficacy in the depressed phase of bipolar disorder, quetiapine in both bipolar I and II [12] and olanzapine in only bipolar I [13].

Lamotrigine is a recently approved mood stabilizer that effectively prevented relapses in patients with bipolar I disorder with recent depressive episodes [14, 15]. Additionally, lamotrigine was an effective maintenance therapy for patients with a predominant depressive polarity in bipolar disorder [16]. Lamotrigine was also reported to be an effective add-on therapy [17]. Furthermore, lamotrigine showed mood-stabilizing potential, because it suppressed weekly mood fluctuations [18]. On the other hand, lamotrigine did not appear to elevate the risk of switching the mood to a manic state [19]. Thus, lamotrigine had the potential to prevent relapse and maintain recovery from depression in 
bipolar disorders, without contributing to the risk of mood switching.

However, practical indication for the monotherapy of lamotrigine in acute bipolar depression seems to be controversial $[20,21]$. An independent meta-analysis suggests a beneficial effect on depressive symptoms in the depressed phase of bipolar depression, especially in patients show severer scores for baseline depression [22]. This study presents evidence of lamotrigine efficacy for treating subsyndromal depression that appeared after manic or mixed hypomanic and depressive episodes and impairing social activity in patients with bipolar I or II disorder.

\section{Case History}

2.1. Case 1. A 42-year-old male high school teacher, started treatment for depression at a clinic in 1997 at 29 years old. For ten years, he experienced several episodes of depression and recovery. He underwent seasonal mood fluctuations, with a trend of euphoria in spring and summer and depression at the beginning of autumn. In August 2007, he became extremely talkative, hyperactive, irritable, and he began to squander money. He was diagnosed with bipolar disorder I according to the Diagnostic and Statistical Manual of Mental Disorders (DSM)-IV-TR. He was suspended from his job and hospitalized. He responded to pharmacotherapy with lithium, valproate, and risperidone, and was discharged in December 2007. After the discharge, he fell into a depression. He complained that it was annoying to do anything, particularly in the mornings. He received antidepressant treatments with milnacipran at the maximal dose of $100 \mathrm{mg} /$ day for three months or $10 \mathrm{mg} /$ day mianserin for 2 weeks, but neither treatment was effective. He could not return to his job due to depression. Next, he was treated with maprotiline at a daily dose of $20 \mathrm{mg}$; four days after starting this treatment, he abruptly experienced manic symptoms, including talkativeness, irritability, money squandering, sleeplessness, and a feeling of intense excitement. In August 2008, he was hospitalized again. Upon evaluation, he received a score of 136 on the CLINICAL GLOBAL IMPRESSION-BP Version (CGI-BP), and he was considered severely ill according to the overall bipolar illness on the Young Mania Rating Scale (YMRS). In October 2008, after undergoing pharmacotherapy, these evaluations were reduced to 4 and minimally ill, respectively. At that time, he was discharged with a prescription of $1000 \mathrm{mg} /$ day lithium, $1200 \mathrm{mg} /$ day valproate, and $3 \mathrm{mg} /$ day clonazepam. However, his depression returned.

In January 2009, he began treatment with lamotrigine at a daily dose of $50 \mathrm{mg}$. The lamotrigine dose was elevated gradually to $100 \mathrm{mg} /$ day; the dose of lithium was reduced to $400 \mathrm{mg} /$ day; the clonazepam was discontinued. After one month of treatment with lamotrigine, his depression was alleviated. His score declined on the Zung Self-Rated Depression Scale (SDS; Figure 1). In April 2009, he began a rehabilitation program in his workplace. In October, the lamotrigine dose was increased to $150 \mathrm{mg} /$ day when his depression worsened, and this treatment was effective

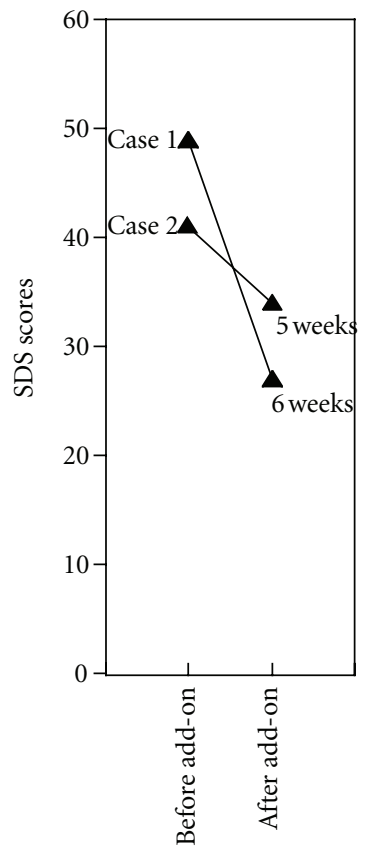

FIGURE 1: SDS scores before and after the add-on treatment with lamotrigine. SDS evaluations were performed before, and at 5 and 6 weeks after beginning lamotrigine.

at preventing further episodes. During the rehabilitation program, no apparent depressive moods or manic states recurred. He returned to his job full time in March, 2011.

2.2. Case 2. A 47-year-old male pharmaceutical advertiser had experienced depression, anxiety, and insomnia, shortly after his transfer to a different branch in May 2006 at 46 years old. He was suspended from his job and received pharmacological treatment in a clinic. In October 2006, he attempted to return to his job, but he failed due to irritability and aggressiveness. During that period, he had difficulty suppressing the urge to declaim people on the street when they displayed bad social manners. Due to depressive symptoms, anxiety, and irritability, he entered a hospital in November, 2008. He was diagnosed with bipolar disorder II according to the DSM-IV-TR. In December 2008, brain magnetic resonance imaging (MRI) indicated bilateral hippocampal atrophy (Figure 2(A)). He was treated with mood stabilizers, including $600 \mathrm{mg} /$ day lithium and $600 \mathrm{mg} /$ day valproate in combination with $30 \mathrm{mg} /$ day amitriptyline. Trihexyphenidyl was also administered to calm a mild tremor in the hands and trunk of the body, which intensified with tension. During the hospitalization, he received a CGI-BP score of 18 , and he was considered moderately ill according to the Overall Bipolar Illness of YMRS. He was discharged in February 2009 with an SDS score of 34, and his CGI-BP and Overall Bipolar Illness of YMRS evaluations were 0 and Normal, respectively.

After the discharge, he complained of depression, dry mouth, and a dull headache in the forehead. In March 2009, the SDS score deteriorated to 41. An add-on treatment of lamotrigine was begun at $25 \mathrm{mg}$ every other day, and this was 

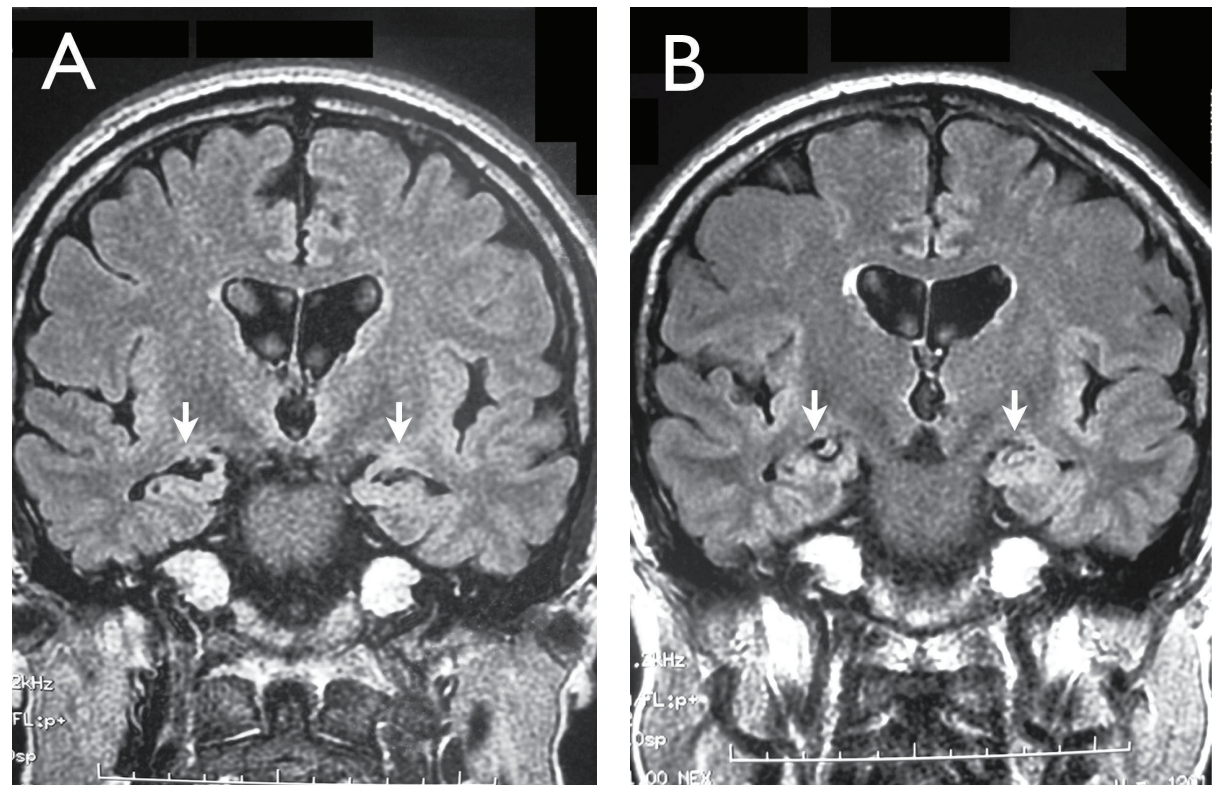

FIGURE 2: Fluid-attenuated inversion recovery MRI images of the brain in Case 2. MRIs were performed (A) in December 2008 and (B) November 2011. Arrows indicate the hippocampus.

increased gradually to $100 \mathrm{mg} /$ day. Conversely, amitriptyline and lithium were tapered down and then ceased. After 5 weeks of the add-on treatment, his depression ameliorated, and the SDS score had reduced to 34 (Figure 1). In addition, the dry mouth and hand tremors had ameliorated. He began a rehabilitation program at the workplace in September, 2009. However, the dull headache continued and intensified when he was tired. In August 2010, olanzapine was added and the patient responded well. In October 2010, he returned to work. In November 2011, MRI analysis showed beneficial changes in the hippocampus (Figure 2(B)).

\section{Discussion}

The present case studies showed that bipolar depression was successfully treated with add-on lamotrigine therapy. Both patients experienced subjective depressive feelings that emerged after a remission from manic or mixed hypomanic and depressive states. Add-on lamotrigine therapy alleviated these symptoms, reduced the SDS scores, and did not cause mood switching to manic or hypomanic states. Both patients recovered normal social activity and returned to their jobs after a period of rehabilitation. Of note, alleviation of subjective depression is critical for improving the QOL.

Case 1 exhibited a high risk of mood switching induced by antidepressants. In addition, seasonal mood instability was noted, a pattern proposed to be characteristic of patients with bipolarity [23].

In case 2, add-on lamotrigine treated depression and anxiety-related tremors. Moreover, the dull headache responded to olanzapine treatment. Olanzapine has been reported to be efficacious for treating comorbid anxiety symptoms in patients with bipolar disorders [24, 25]. It was suggested that olanzapine had neuroprotective or neurotrophic properties [26]. The response of this patient suggested that the treatment ameliorated hippocampal atrophy. These findings were consistent with previous findings $[27,28]$. However, although the neurotrophic effects of olanzapine might be relevant to the recovery, mood stabilizers also have neurotrophic effects [29].

The present cases described patients with jobs that required high intellectual performance. Therefore, these bipolar disorders impacted job performance due to the effects on neurocognitive functions, including impairments in executive function, verbal learning, and processing speed [30-32]. We speculate that the improvement in subjective depression may have contributed to neurocognitive recovery. In the argument whether pharmacotherapy affects neurocognitive function [33, 34], lamotrigine was suggested to confer a favorable neurocognitive profile [35].

In conclusion, the present case studies demonstrated that add-on lamotrigine improved subsyndromal depressive symptoms and improved the QOL in bipolar I and II disorders. Thus, subsyndromal depression may be practical indication for the use of lamotrigine.

\section{Conflict of Interests}

The authors declare that there is no conflict of interests.

\section{References}

[1] L. L. Judd, H. S. Akiskal, P. J. Schettler et al., "A prospective investigation of the natural history of the long-term weekly symptomatic status of bipolar II disorder," Archives of General Psychiatry, vol. 60, no. 3, pp. 261-269, 2003.

[2] L. L. Judd, H. S. Akiskal, P. J. Schettler et al., "The long-term natural history of the weekly symptomatic status of bipolar 
I disorder," Archives of General Psychiatry, vol. 59, no. 6, pp. 530-537, 2002.

[3] R. W. Kupka, L. L. Altshuler, W. A. Nolen et al., "Three times more days depressed than manic or hypomanic in both bipolar I and bipolar II disorder," Bipolar Disorders, vol. 9, no. 5, pp. 531-535, 2007.

[4] J. F. Goldberg and M. Harrow, "Subjective life satisfaction and objective functional outcome in bipolar and unipolar mood disorders: a longitudinal analysis," Journal of Affective Disorders, vol. 89, no. 1-3, pp. 79-89, 2005.

[5] A. R. Rosa, C. M. Bonnín, G. H. Vázquez et al., "Functional impairment in bipolar II disorder: is it as disabling as bipolar I?" Journal of Affective Disorders, vol. 127, no. 1-3, pp. 71-76, 2010.

[6] E. Vieta, R. de Arce, M. A. Jiménez-Arriero, A. Rodriguez, V. Balanzá, and S. Cobaleda, "Detection of subclinical depression in bipolar disorder: a cross-sectional, 4-month prospective follow-up study at community mental health services (SINDEPRES)," Journal of Clinical Psychiatry, vol. 71, no. 11, pp. 1465-1474, 2010.

[7] R. M. Post, G. S. Leverich, W. A. Nolen et al., "A reevaluation of the role of antidepressants in the treatment of bipolar depression: data from the Stanley Foundation Bipolar Network," Bipolar Disorders, vol. 5, no. 6, pp. 396-406, 2003.

[8] M. M. Sidor and G. M. MacQueen, "Antidepressants for the acute treatment of bipolar depression: a systematic review and meta-analysis," Journal of Clinical Psychiatry, vol. 72, no. 2, pp. 156-167, 2011.

[9] M. A. Frye, G. Helleman, S. L. McElroy et al., "Correlates of treatment-emergent mania associated with antidepressant treatment in bipolar depression," American Journal of Psychiatry, vol. 166, no. 2, pp. 164-172, 2009.

[10] E. Vieta, J. Angst, C. Reed, J. Bertsch, and J. M. Haro, "Predictors of switching from mania to depression in a large observational study across Europe (EMBLEM)," Journal of Affective Disorders, vol. 118, no. 1-3, pp. 118-123, 2009.

[11] E. Vieta, J. Locklear, O. Günther et al., "Treatment options for bipolar depression: a systematic review of randomized, controlled trials," Journal of Clinical Psychopharmacology, vol. 30, no. 5, pp. 579-590, 2010.

[12] J. R. Calabrese, P. E. Keck Jr., W. Macfadden et al., "A randomized, double-blind, placebo-controlled trial of quetiapine in the treatment of bipolar I or II depression," American Journal of Psychiatry, vol. 162, no. 7, pp. 1351-1360, 2005.

[13] M. Tohen, E. Vieta, J. Calabrese et al., "Efficacy of olanzapine and olanzapine-fluoxetine combination in the treatment of bipolar I depression," Archives of General Psychiatry, vol. 60, no. 11, pp. 1079-1088, 2003.

[14] C. L. Bowden, J. R. Calabrese, G. Sachs et al., "A placebocontrolled 18-month trial of lamotrigine and lithium maintenance treatment in recently manic or hypomanic patients with bipolar I disorder," Archives of General Psychiatry, vol. 60, no. 4, pp. 392-400, 2003.

[15] J. R. Calabrese, C. L. Bowden, G. Sachs et al., "A placebocontrolled 18-month trial of lamotrigine and lithium maintenance treatment in recently depressed patients with bipolar I disorder," Journal of Clinical Psychiatry, vol. 64, no. 9, pp. 1013-1024, 2003.

[16] D. Popovic, M. Reinares, J. M. Goikolea, C. M. Bonnin, A. Gonzalez-Pinto, and E. Vieta, "Polarity index of pharmacological agents used for maintenance treatment of bipolar disorder," European Neuropsychopharmacology, vol. 22, no. 5, pp. 339-346, 2012.
[17] M. L. M. van der Loos, P. G. H. Mulder, E. G. T. M. Hartong et al., "Efficacy and safety of lamotrigine as add-on treatment to lithium in bipolar depression: a multicenter, double-blind, placebo-controlled trial," Journal of Clinical Psychiatry, vol. 70, no. 2, pp. 223-231, 2009.

[18] J. F. Goldberg, C. L. Bowden, J. R. Calabrese et al., "Sixmonth prospective life charting of mood symptoms with lamotrigine monotherapy versus placebo in rapid cycling bipolar disorder," Biological Psychiatry, vol. 63, no. 1, pp. 125130, 2008.

[19] J. F. Goldberg, J. R. Calabrese, B. R. Saville et al., "Mood stabilization and destabilization during acute and continuation phase treatment for bipolar I disorder with lamotrigine or placebo," Journal of Clinical Psychiatry, vol. 70, no. 9, pp. 12731280, 2009.

[20] J. R. Calabrese, C. L. Bowden, G. S. Sachs, J. A. Ascher, E. Monaghan, and G. D. Rudd, "A double-blind placebocontrolled study of lamotrigine monotherapy in outpatients with bipolar I depression," Journal of Clinical Psychiatry, vol. 60 , no. 2, pp. 79-88, 1999.

[21] J. R. Calabrese, R. F. Huffman, R. L. White et al., "Lamotrigine in the acute treatment of bipolar depression: results of five double-blind, placebo-controlled clinical trials," Bipolar Disorders, vol. 10, no. 2, pp. 323-333, 2008.

[22] J. R. Geddes, J. R. Calabreso, and G. M. Goodwin, "Lamotrigine for treatment of bipolar depression: independent metaanalysis and meta-regression of individual patient data from five randomised trials," British Journal of Psychiatry, vol. 194, no. 1, pp. 4-9, 2009.

[23] T. Sato, R. Bottlender, M. Sievers, and H. J. Möller, "Distinct seasonality of depressive episodes differentiates unipolar depressive patients with and without depressive mixed states," Journal of Affective Disorders, vol. 90, no. 1, pp. 1-5, 2006.

[24] J. J. Rakofsky and B. W. Dunlop, "Treating nonspecific anxiety and anxiety disorders in patients with bipolar disorder: a review," Journal of Clinical Psychiatry, vol. 72, no. 1, pp. 8190, 2011.

[25] M. Tohen, J. Calabrese, E. Vieta et al., "Effect of comorbid anxiety on treatment response in bipolar depression," Journal of Affective Disorders, vol. 104, no. 1-3, pp. 137-146, 2007.

[26] A. González-Pinto, F. Mosquera, A. Palomino et al., "Increase in brain-derived neurotrophic factor in first episode psychotic patients after treatment with atypical antipsychotics," International Clinical Psychopharmacology, vol. 25, no. 4, pp. 241-245, 2010.

[27] H. P. Blumberg, J. Kaufman, A. Martin et al., "Amygdala and hippocampal volumes in adolescents and adults with bipolar disorder," Archives of General Psychiatry, vol. 60, no. 12, pp. 1201-1208, 2003.

[28] L. C. Foland, L. L. Altshuler, C. A. Sugar et al., "Increased volume of the amygdala and hippocampus in bipolar patients treated with lithium," NeuroReport, vol. 19, no. 2, pp. 221-224, 2008.

[29] H. K. Manji, G. J. Moore, and G. Chen, "Clinical and preclinical evidence for the neurotrophic effects of mood stabilizers: implications for the pathophysiology and treatment of manicdepressive illness," Biological Psychiatry, vol. 48, no. 8, pp. 740754, 2000.

[30] C. M. Bonnin, J. Sanchez-Moreno, A. Martinez-Aran et al., "Subthreshold symptoms in bipolar disorder: impact on neurocognition, quality of life and disability," Journal of Affective Disorders, vol. 136, no. 3, pp. 650-659, 2012.

[31] K. E. Burdick, J. F. Goldberg, and M. Harrow, "Neurocognitive dysfunction and psychosocial outcome in patients with 
bipolar I disorder at 15 year follow-up," Acta Psychiatrica Scandinavica, vol. 122, no. 6, pp. 499-506, 2010.

[32] M. Mur, M. J. Portella, A. Martínez-Arán, J. Pifarré, and E. Vieta, "Persistent neuropsychological deficit in euthymic bipolar patients: executive function as a core deficit," Journal of Clinical Psychiatry, vol. 68, no. 7, pp. 1078-1086, 2007.

[33] C. López-Jaramillo, J. Lopera-Vásquez, J. Ospina-Duque et al., "Lithium treatment effects on the neuropsychological functioning of patients with bipolar I disorder," Journal of Clinical Psychiatry, vol. 71, no. 8, pp. 1055-1060, 2010.

[34] A. P. Wingo, T. S. Wingo, P. D. Harvey, and R. J. Baldessarini, "Effects of lithium on cognitive performance: a meta-analysis," Journal of Clinical Psychiatry, vol. 70, no. 11, pp. 1588-1597, 2009.

[35] C. Daban, A. Martínez-Arán, C. Torrent et al., "Cognitive functioning in bipolar patients receiving lamotrigine: preliminary results," Journal of Clinical Psychopharmacology, vol. 26, no. 2, pp. 178-181, 2006. 


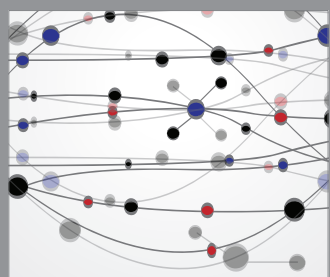

The Scientific World Journal
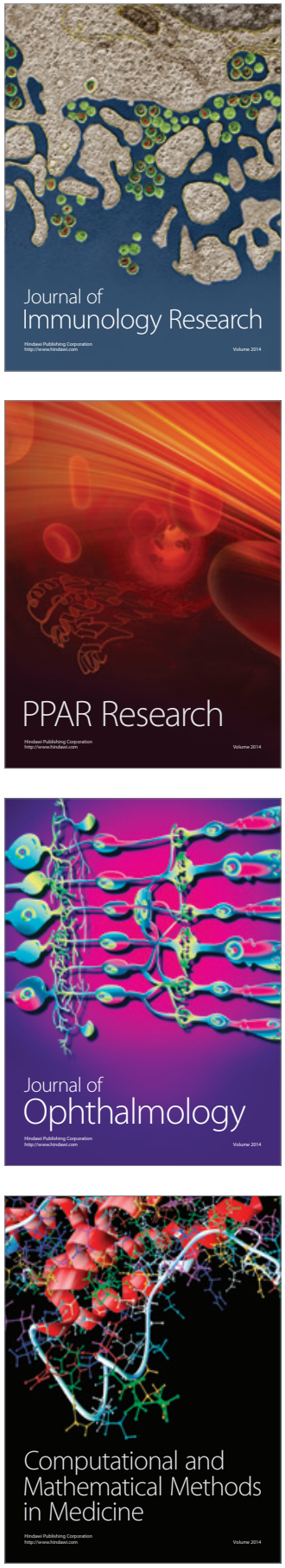

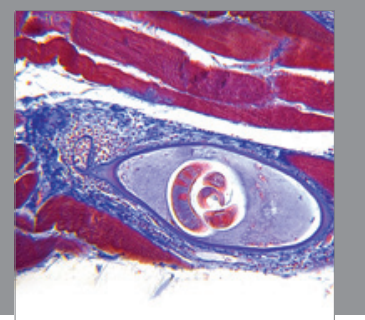

Gastroenterology

Research and Practice
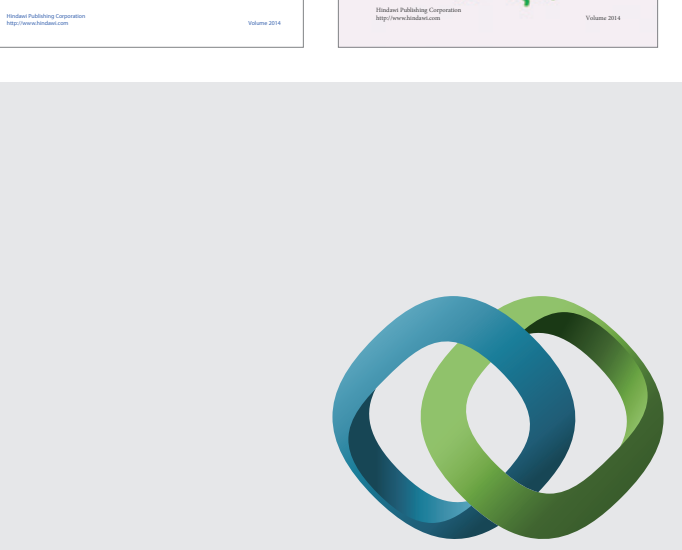

\section{Hindawi}

Submit your manuscripts at

http://www.hindawi.com
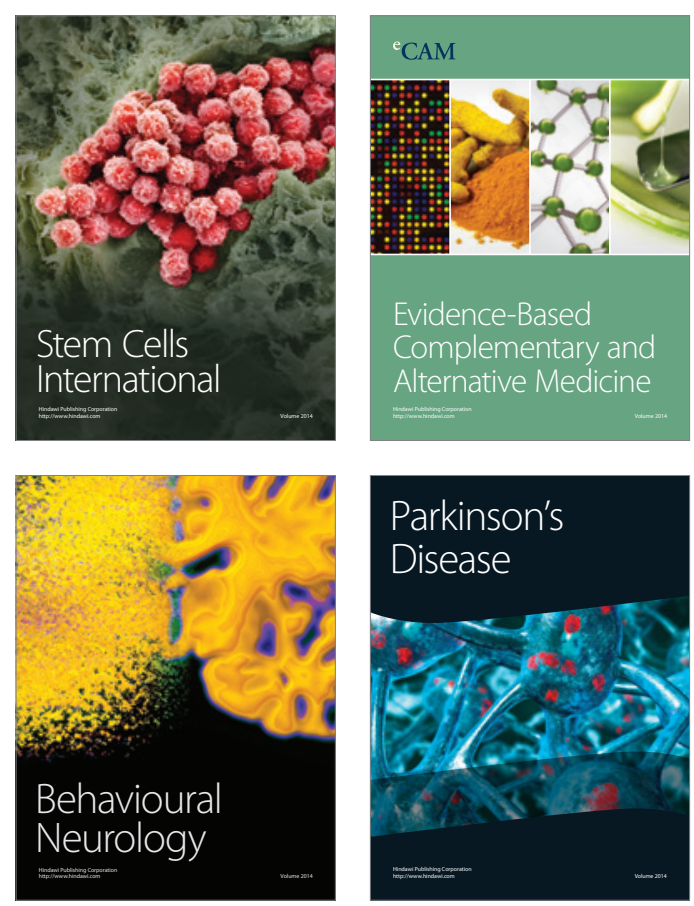

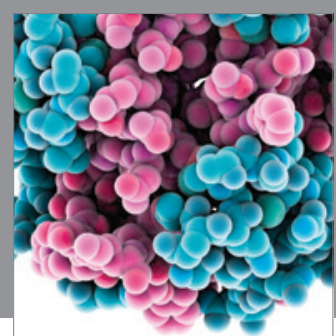

Journal of
Diabetes Research

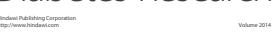

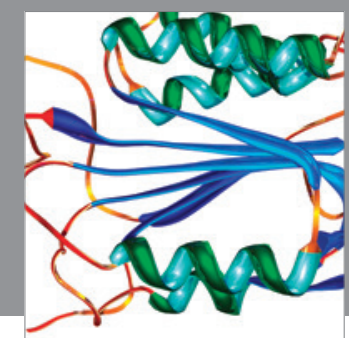

Disease Markers
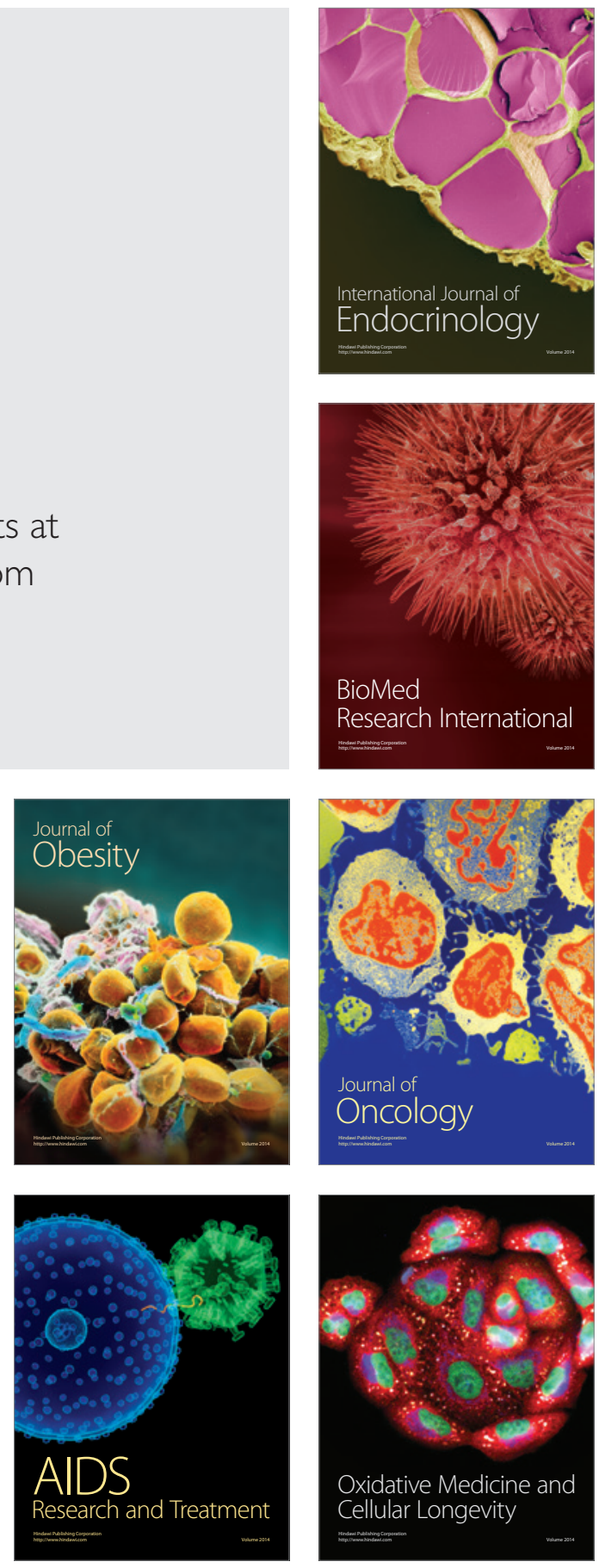